\title{
Optimal Dose of Epidural Dexmedetomidine Added to Ropivacaine for Epidural Labor Analgesia: A Pilot Study
}

\author{
Zhang Wangping and Ren Ming \\ Department of Anesthesiology, Affiliated Women and Children's Hospital of Jiaxing University, Jiaxing, China \\ Correspondence should be addressed to Ren Ming; 1910773504@qq.com
}

Received 30 December 2016; Accepted 27 April 2017; Published 1 June 2017

Academic Editor: Armando Zarrelli

Copyright (C) 2017 Zhang Wangping and Ren Ming. This is an open access article distributed under the Creative Commons Attribution License, which permits unrestricted use, distribution, and reproduction in any medium, provided the original work is properly cited.

\begin{abstract}
Background. Dexmedetomidine combined with local anesthetics can decrease the concentration of epidural ropivacaine. However, the optimal dose of epidural dexmedetomidine combined with ropivacaine for labor analgesia is still uncertain. This study investigated the effect of adding different dose of epidural dexmedetomidine to ropivacaine during epidural labor analgesia. Methods. One hundred women were randomly assigned to one of the four groups (Groups A, B, C, and D received $0.25,0.5,0.75$, and $1 \mu \mathrm{g} / \mathrm{ml}$ of dexmedetomidine plus $0.1 \%$ ropivacaine, resp.). The onset of epidural anesthesia and stages of labor were studied, and pain was assessed using a visual analogue scale (VAS). Hemodynamic parameters and fetal heart rate were monitored. Apgar scores and umbilical artery $\mathrm{pH}$ were recorded. The side effects, if any, were recorded also. Results. The addition of $0.25,0.5$, and $0.75 \mu \mathrm{g} / \mathrm{ml}$ of dexmedetomidine to $0.1 \%$ ropivacaine provided safe and effective analgesia, but $1 \mu \mathrm{g} / \mathrm{ml}$ of dexmedetomidine resulted in increasing incidence of motor block. The hemodynamic parameters were similar between groups $(P>0.05)$. Side effects in Group $\mathrm{D}$ were significantly higher than those in the other three groups $(P<0.05)$. Conclusions. When dexmedetomidine is combined with $0.1 \%$ ropivacaine, the optimal concentration of dexmedetomidine is $0.5 \mu \mathrm{g} / \mathrm{ml}$ for epidural labor analgesia (this trial is registered with ChiCTR-OPC-16008548).
\end{abstract}

\section{Introduction}

Epidural labor analgesia is the most common technique for labor pain management. Ropivacaine has been used commonly for epidural labor analgesia, because of less motor block and stable hemodynamics. Dexmedetomidine, an $\alpha_{2}-$ agonist for $\alpha_{2}$-adrenergic receptors, possesses sedative and analgesic properties without respiratory depressant effect [1] and enhances their effects without increasing the incidence of side effects when added to local anesthetic agents [2-8]. At present, dexmedetomidine, although approved for intravenous use only, has been successfully used in neuraxial block and epidural block in experimental and clinical studies with less side effects $[9,10]$. However, the study of dexmedetomidine is scarce in the obstetric population, and the optimal dose of epidural dexmedetomidine combined with ropivacaine for labor analgesia is still uncertain. The present study was designed to investigate the effect of adding different dose of epidural dexmedetomidine to ropivacaine during labor analgesia.

\section{Methods}

Ethical approval for this study was provided by the Ethical Committee of Jiaxing Hospital, Jiaxing, China (Chairman Professor L. Xia) on 16 July 2016. Informed consent was signed by the parturient women. One hundred parturient women (gestational weeks $\geq 37$ ) with ASA I or II were enrolled in this prospective, single-blinded study. Exclusion criteria were as follows: ASA grades III-V, contraindication to epidural anesthesia, and patients undergoing caesarean section. One hundred parturient women were randomly assigned to one of four groups (Group A, Group B, Group C, and Group D) by using a computer-generated list $(n=25)$.

Vitals (heart rate, blood pressure, $\mathrm{SpO}_{2}$, and respiratory rate) were monitored immediately after entering delivery room every $5 \mathrm{~min}$ till the end of labor, and venous access was established. The epidural analgesia was performed at $\mathrm{L}_{2-3}$ interspace by an 18-gauge Tuohy needle using the method of loss of resistance to air in left lateral position. Then, an 


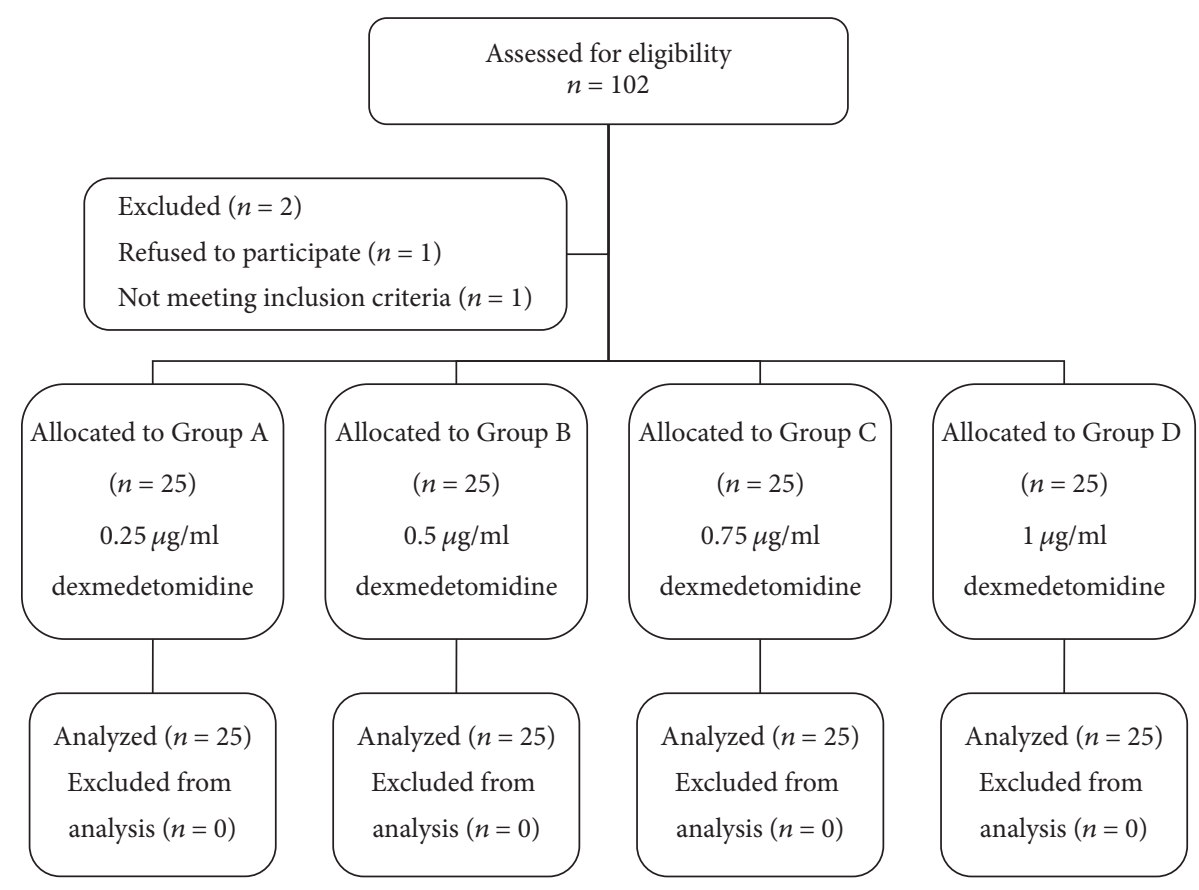

FIgURE 1: Flow diagram of study.

epidural catheter was inserted $3-4 \mathrm{~cm}$ cephalad into epidural space. Five minutes after a test dose of $5 \mathrm{ml}$ of $1 \%$ lidocaine, parturient women received $8 \mathrm{ml}$ of $0.25 \mu \mathrm{g} / \mathrm{ml}, 0.5 \mu \mathrm{g} / \mathrm{ml}$, $0.75 \mu \mathrm{g} / \mathrm{ml}$, and $1 \mu \mathrm{g} / \mathrm{ml}$ of dexmedetomidine, respectively, combined with $0.1 \%$ ropivacaine as loading dose, then infusing continuously this mixed solution at rate of $8 \mathrm{ml} / \mathrm{h}$. A bolus of $8 \mathrm{ml}$ (lockout time of $15 \mathrm{~min}$ ) was administrated when visual analogue scale (VAS) scores $\geq 7$.

Onset time of analgesia, blood pressure, heart rate, umbilical artery $\mathrm{pH}$, fetal heart rate abnormalities, and Apgar scores were noted and analyzed. Duration of stage of labor and blood loss were also recorded. The onset of analgesia was defined as the time between the end of the epidural injection and the absence of pain at the T10 dermatome every 60 seconds by pinprick. The efficacy of the epidural analgesia was assessed at $30 \mathrm{~min}$ after epidural injection by VAS score $(0=$ no pain, 10 = worst pain). Motor block was assessed using a modified Bromage score $(0=$ no motor loss, $1=$ inability to flex hip, 2 = inability to flex hip and knee, and 3 = inability to flex hip, knee, and ankle). The side effects including hypotension, sedation, nausea or vomiting, uroschesis, and fetal bradycardia were also studied. Respiratory depression was defined as a decrease in $\mathrm{SpO}_{2}$ of $<94 \%$. Fall in systolic blood pressure and heart rate by $>20 \%$ from the baseline value was defined as hypotension or bradycardia, respectively.

The level of sedation was evaluated using Ramsay level of sedation scale [11] ((1) patient anxious, agitated, or restless; (2) patient cooperative, oriented, and tranquil alert; (3) patient responding to commands; (4) asleep, but with brisk response to light glabellar tap or loud auditory stimulus; (5) asleep, sluggish response to light glabellar tap or loud auditory stimulus; (6) asleep, no response). The level of sedation was evaluated every 30 min during labor using Ramsay level of sedation scale till the parturient woman was discharged from the delivery room. Excessive sedation was defined as score greater than 4 .

2.1. Statistical Analysis. Statistical analysis was performed with SPSS 17.0 (SPSS Inc., Chicago, USA). Numerical variables were presented as mean and standard deviation (SD). Categorical data were presented as numbers. Means normally distributed were analyzed by one-way ANOVA, nonnormally distributed means were analyzed by Mann-Whitney $U$ test, and categorical data were analyzed by Chi-square test. Statistical significance was defined as $P<0.05$.

\section{Results}

One hundred parturient women were enrolled in the study. No parturient woman was excluded for any reason (Figure 1). There were no differences in parturient women's demographic data including age, body weight, height, and gestation age $(P>0.05)$ (Table 1$)$. The hemodynamic data, blood loss, mode of delivery, time of stage of labor, and onset time of analgesia were not significantly different between the four groups $(P>0.05)$ (Table 1). Neonatal Apgar score, umbilical artery $\mathrm{pH}$, and umbilical artery $\mathrm{PaO}_{2}$ were similar in the four groups; there were no significant differences between the groups $(P>0.05)$ (Table 1$)$.

The analgesic effects were enhanced with the increase of dose of dexmedetomidine in a certain range (Figure 2 ). There was significant difference in analgesic effects after $2 \mathrm{~cm}$ of cervical dilatation between Group A and Group D, but there was no significant difference in analgesic effects in Group B, 
TABLE 1: Data of parturient women and neonatal Apgar score.

\begin{tabular}{|c|c|c|c|c|c|}
\hline Index & Group A & Group B & Group C & Group D & $P$ \\
\hline Maternal age (year) & $28.4 \pm 3.5$ & $29.1 \pm 4.2$ & $27.8 \pm 3.8$ & $27.5 \pm 2.9$ & 0.521 \\
\hline Weight $(\mathrm{kg})$ & $71.3 \pm 5.7$ & $74.3 \pm 6.8$ & $69.3 \pm 4.5$ & $72.6 \pm 7.1$ & 0.258 \\
\hline Height $(\mathrm{cm})$ & $159.3 \pm 3.4$ & $161.5 \pm 4.5$ & $158.7 \pm 3.6$ & $162.2 \pm 4.3$ & 0.586 \\
\hline Gestational age (week) & $38.7 \pm 1.8$ & $39.3 \pm 2.2$ & $38.2 \pm 1.7$ & $39.1 \pm 2.1$ & 0.321 \\
\hline Onset time of analgesia ( $\mathrm{min}$ ) & $15.8 \pm 3.6$ & $15.4 \pm 4.1$ & $15.0 \pm 3.8$ & $14.8 \pm 3.4$ & 0.723 \\
\hline Time of the first stage of labor ( $\mathrm{min}$ ) & $358.7 \pm 86.5$ & $372.4 \pm 95.8$ & $381.7 \pm 89.4$ & $388.2 \pm 85.2$ & 0.272 \\
\hline Time of the second stage of labor (min) & $39.8 \pm 12.6$ & $41.2 \pm 8.6$ & $40.5 \pm 9.8$ & $42.4 \pm 11.5$ & 0.681 \\
\hline Blood loss (ml) & $205.6 \pm 19.5$ & $198.6 \pm 24.8$ & $194.5 \pm 26.7$ & $192.2 \pm 21.4$ & 0.728 \\
\hline \multicolumn{6}{|l|}{ Mode of delivery (vaginal/cesarean) } \\
\hline Vaginal $(n)$ & 22 & 23 & 24 & 22 & 0.876 \\
\hline Cesarean $(n)$ & 3 & 2 & 1 & 3 & 0.496 \\
\hline$>20 \%$ decrease SBP $(n)$ & 0 & 0 & 0 & 0 & 1 \\
\hline$>20 \%$ decrease HR $(n)$ & 0 & 0 & 0 & 0 & 1 \\
\hline \multicolumn{6}{|l|}{ Neonatal Apgar score } \\
\hline At 1st min (score) & $9.0 \pm 0.62$ & $8.8 \pm 0.58$ & $8.9 \pm 0.56$ & $8.7 \pm 0.47$ & 0.686 \\
\hline At 5 th $\min$ (score) & $9.7 \pm 0.81$ & $9.6 \pm 0.72$ & $9.5 \pm 0.68$ & $9.6 \pm 0.75$ & 0.564 \\
\hline Umbilical artery $\mathrm{pH}$ & $7.24 \pm 0.08$ & $7.23 \pm 0.06$ & $7.21 \pm 0.06$ & $7.21 \pm 0.07$ & 0.576 \\
\hline Umbilical artery $\mathrm{PaO}_{2}(\mathrm{mmHg})$ & $32.4 \pm 6.5$ & $31.6 \pm 6.3$ & $31.8 \pm 5.9$ & $30.2 \pm 6.1$ & 0.277 \\
\hline
\end{tabular}

Data were presented as mean \pm standard deviations or numbers. Compared between the four groups, $P>0.05$.

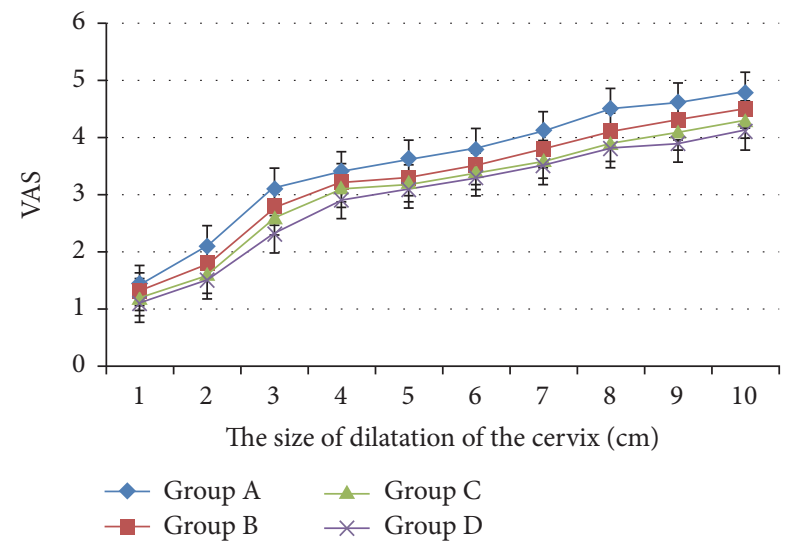

FIGURE 2: Comparison of analgesic efficacy between the groups.

Group C, and Group D. Motor block happened in Group $\mathrm{D}$ and Group C, but none in the other groups (Table 2). There was no significant difference in Ramsay sedation scores between the groups. Besides, there was no significant difference in the $\mathrm{SpO}_{2}$ and respiratory depression between the groups during labor.

Higher proportion of parturient women in four groups fall in systolic blood pressure and heart rate more than $20 \%$ of baseline value after epidural analgesia, but there were no significant differences in systolic blood pressure and heart rate between the groups. The incidence of shivering, nausea or vomiting, uroschesis, and fetal bradycardia was not significant difference between the groups.
TABLE 2: Side effects of anesthesia.

\begin{tabular}{lcccc}
\hline Index & Group A & Group B & Group C & Group D \\
\hline Nausea and vomiting & 0 & 0 & 0 & 0 \\
Uroschesis & 0 & 0 & 0 & 0 \\
Hypotension & 0 & 0 & 0 & 1 \\
Fetal bradycardia & 0 & 0 & 0 & 0 \\
Respiratory depression & 0 & 0 & 0 & 0 \\
Bromage score $(0 / 1 / 2 / 3)$ & $25 / 0 / 0 / 0$ & $25 / 0 / 0 / 0$ & $24 / 1 / 0 / 0$ & $23 / 2 / 0 / 0$ \\
Excessive sedation & 0 & 0 & 0 & 0 \\
\hline
\end{tabular}

Data were presented as numbers. Compared between the four groups, $P>$ 0.05 .

\section{Discussion}

The ideal epidural analgesia should not only provide parturient women with satisfactory analgesia, but also reduce side effects of the mater and newborn, such as motor block, nausea and vomiting, pruritus, uroschesis, and fetal bradycardia. Dexmedetomidine has been used for enhancing the potency of epidural ropivacaine and decreasing the requirements of analgesic. In this study, we found that all of the four groups achieved good effects when four different concentrations of dexmedetomidine were added to epidural ropivacaine, and the optimal dose of epidural dexmedetomidine is $0.5 \mu \mathrm{g} / \mathrm{ml}$.

It is well known that fentanyl can reduce the concentration of epidural ropivacaine and decrease the requirement of ropivacaine for epidural labor analgesia. In this study, we found that the requirements of local anesthetic were reduced also when ropivacaine is combined with dexmedetomidine for epidural labor analgesia. It was according to many 
clinical trials in nonobstetric patients. Analgesic effects were enhanced with the increase of dose of dexmedetomidine in a certain range. Dexmedetomidine enhanced the analgesic effects without increasing the incidence of side effects when added to ropivacaine. Its mechanism of action is that it possesses selectivity, especially for an $\alpha_{2}$ receptor, which causes it to be an effective sedative and analgesic agent [12]. Compared to fentanyl, dexmedetomidine had less pruritus and less nausea and vomiting during epidural labor analgesia. It could be used safely for epidural labor analgesia. In this study, we found that analgesic efficacy in Group D was significantly better than in the other three groups, but the side effects in Group D were obviously higher than in other three groups. It was obvious that analgesic efficacy in Group A was not perfect because of lower dose of dexmedetomidine. Motor block could occur probably when $0.75 \mu \mathrm{g} / \mathrm{ml}$ or $1 \mu \mathrm{g} / \mathrm{ml}$ of dexmedetomidine was used for epidural labor analgesia. In this study, there was no significant difference in the $\mathrm{SpO}_{2}$ and umbilical artery $\mathrm{PaO}_{2}$ between the groups during labor. Dexmedetomidine does not cause significant respiratory depression despite providing good sedation resulting in wide safety margins [13]. In our study, Ramsay sedation scores were similar in the four groups during labor, ranging from 2 to 4 , and excessive sedation score was not found. Therefore, this study could indicate that $0.5 \mu \mathrm{g} / \mathrm{ml}$ of dexmedetomidine may be the optimal concentration for epidural labor analgesia (http://www.chictr.org.cn).

Limitation. In vitro study demonstrated that dexmedetomidine has the potential to enhance the frequency of uterine contractions [14]. The effect of dexmedetomidine on parturient women and fetus needs further clinical research in obstetric epidural anesthesia [15].

In summary, we could get the conclusion that $0.5 \mu \mathrm{g} / \mathrm{mL}$ of dexmedetomidine may be the optimal concentration for parturient women in epidural labor analgesia when combined with $0.1 \%$ ropivacaine.

\section{Conflicts of Interest}

There are no conflicts of interest.

\section{Acknowledgments}

This work was supported by Zhejiang Clinical Medical Research Foundation (2015-ZYC-A71).

\section{References}

[1] A. M. El-Hennawy, A. M. Abd-Elwahab, A. M. Abd-Elmaksoud, H. S. El-Ozairy, and S. R. Boulis, "Addition of clonidine or dexmedetomidine to bupivacaine prolongs caudal analgesia in children," British Journal of Anaesthesia, vol. 103, no. 2, pp. 268274, 2009.

[2] T. Yoshitomi, A. Kohjitani, S. Maeda, H. Higuchi, M. Shimada, and T. Miyawaki, "Dexmedetomidine enhances the local anesthetic action of lidocaine via an $\alpha$-2a adrenoceptor," Anesthesia and Analgesia, vol. 107, no. 1, pp. 96-101, 2008.
[3] R. D’Angelo, L. S. Dean, G. C. Meister, and K. E. Nelson, "Neostigmine combined with bupivacaine, clonidine, and sufentanil for spinal labor analgesia," Anesthesia and Analgesia, vol. 93, no. 6, pp. 1560-1564, 2001.

[4] A. T.-H. Sia, "Optimal dose of intrathecal clonidine added to sufentanil plus bupivacaine for labour analgesia," Canadian Journal of Anesthesia, vol. 47, no. 9, pp. 875-880, 2000.

[5] J. C. Eisenach, M. De Kock, and W. Klimscha, " $\alpha 2-$ Adrenergic agonists for regional anesthesia: a clinical review of clonidine (1984-1995)," Anesthesiology, vol. 85, no. 3, pp. 655-674, 1996.

[6] S. J. S. Bajwa, V. Arora, J. Kaur, A. Singh, and S. S. Parmar, "Comparative evaluation of dexmedetomidine and fentanyl for epidural analgesia in lower limb orthopedic surgeries," Saudi Journal of Anaesthesia, vol. 5, no. 4, pp. 365-370, 2011.

[7] N. Sethi, D. Pant, A. Dutta, A. Koul, J. Sood, and P. T. Chugh, "Comparison of caudal epidural block and ultrasonographyguided transversus abdominis plane block for pain relief in children undergoing lower abdominal surgery," Journal of Clinical Anesthesia, vol. 33, pp. 322-329, 2016.

[8] S. R. Arain, R. M. Ruehlow, T. D. Uhrich, and T. J. Ebert, "The efficacy of dexmedetomidine versus morphine for postoperative analgesia after major inpatient surgery," Anesthesia and Analgesia, vol. 98, no. 1, pp. 153-158, 2004.

[9] A. M. Vieira, T. B. Schnaider, A. C. Brandão, F. A. Pereira, E. D. Costa, and C. E. P. Fonseca, "Epidural clonidine or dexmedetomidine for post-cholecystectomy analgesia and sedation," Revista Brasileira de Anestesiologia, vol. 54, no. 4, pp. 473-478, 2004.

[10] T. B. Schnaider, A. M. Vieira, A. C. Aguiar Brandão, and M. V. Tonante Lobo, "Intraoperative analgesic effect of epidural ketamine, clonidine or dexmedetomidine for upper abdominal surgery," Revista Brasileira de Anestesiologia, vol. 55, no. 5, pp. 525-531, 2005.

[11] M. A. Ramsay, T. M. Savege, B. R. Simpson, and R. Goodwin, "Controlled sedation with alphaxalone-alphadolone," British Medical Journal, vol. 2, no. 920, pp. 656-659, 1974.

[12] B. Civantos Calzada and A. A. de Artiñano, "Alpha-adrenoceptor subtypes," Pharmacological Research, vol. 44, no. 3, pp. 195-208, 2001.

[13] C. N. Dinesh, N. A. Sai Tej, B. Yatish, V. S. Pujari, R. M. Mohan Kumar, and C. V. R. Mohan, "Effects of intravenous dexmedetomidine on hyperbaric bupivacaine spinal anesthesia: a randomized study," Saudi Journal of Anaesthesia, vol. 8, no. 2, pp. 202208, 2014.

[14] A. T. Sia, K. Kwek, and G. S. Yeo, “The in vitro effects of clonidine and dexmedetomidine on human myometrium," International Journal of Obstetric Anesthesia, vol. 14, no. 2, pp. 104-107, 2005.

[15] S. Konakci, T. Adanir, G. Yilmaz, and T. Rezanko, “The efficacy and neurotoxicity of dexmedetomidine administered via the epidural route," European Journal of Anaesthesiology, vol. 25, no. 5, pp. 403-409, 2008. 


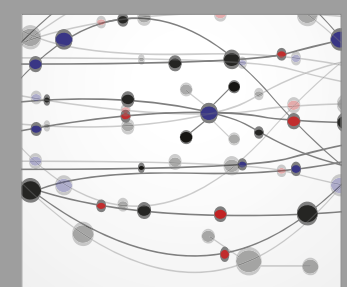

The Scientific World Journal
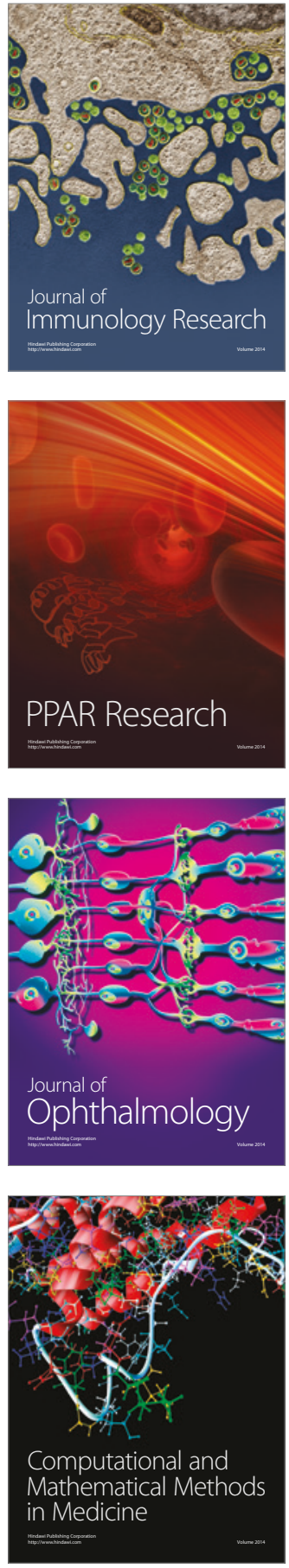

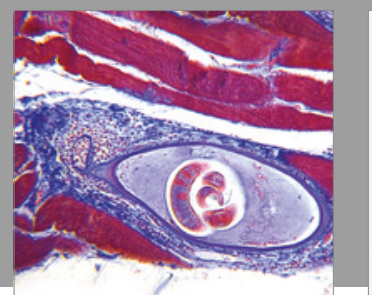

Gastroenterology Research and Practice
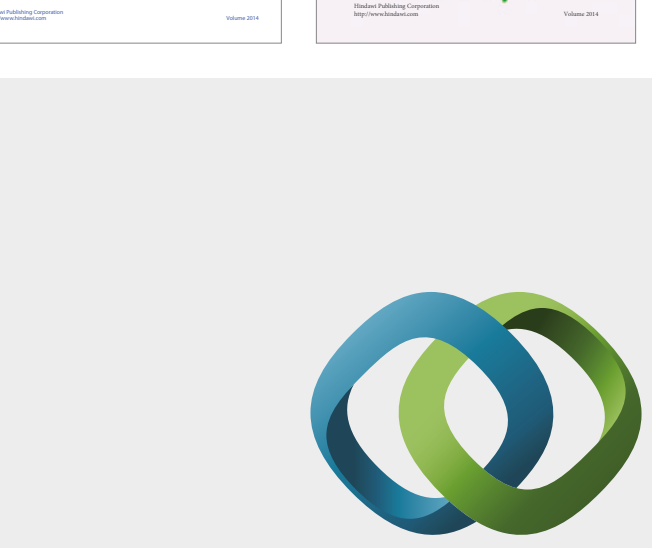

\section{Hindawi}

Submit your manuscripts at

https://www.hindawi.com
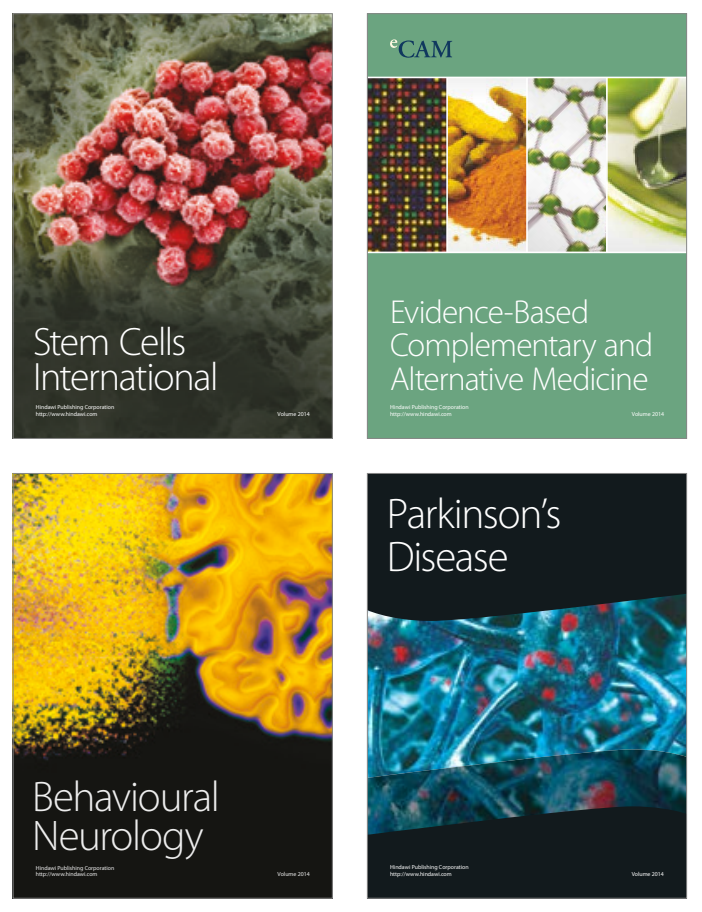
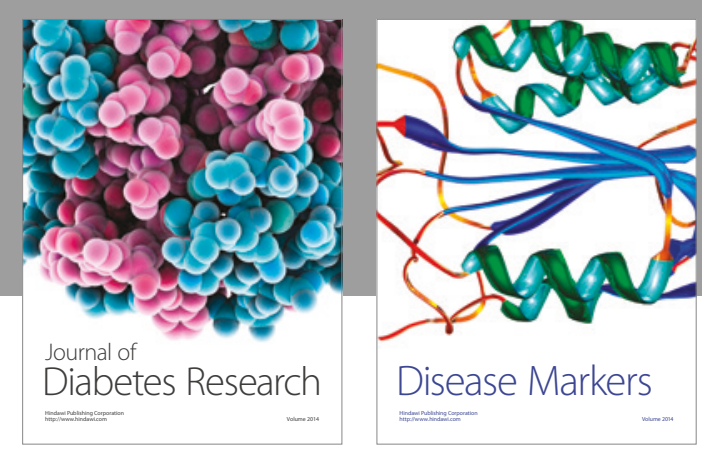

Disease Markers
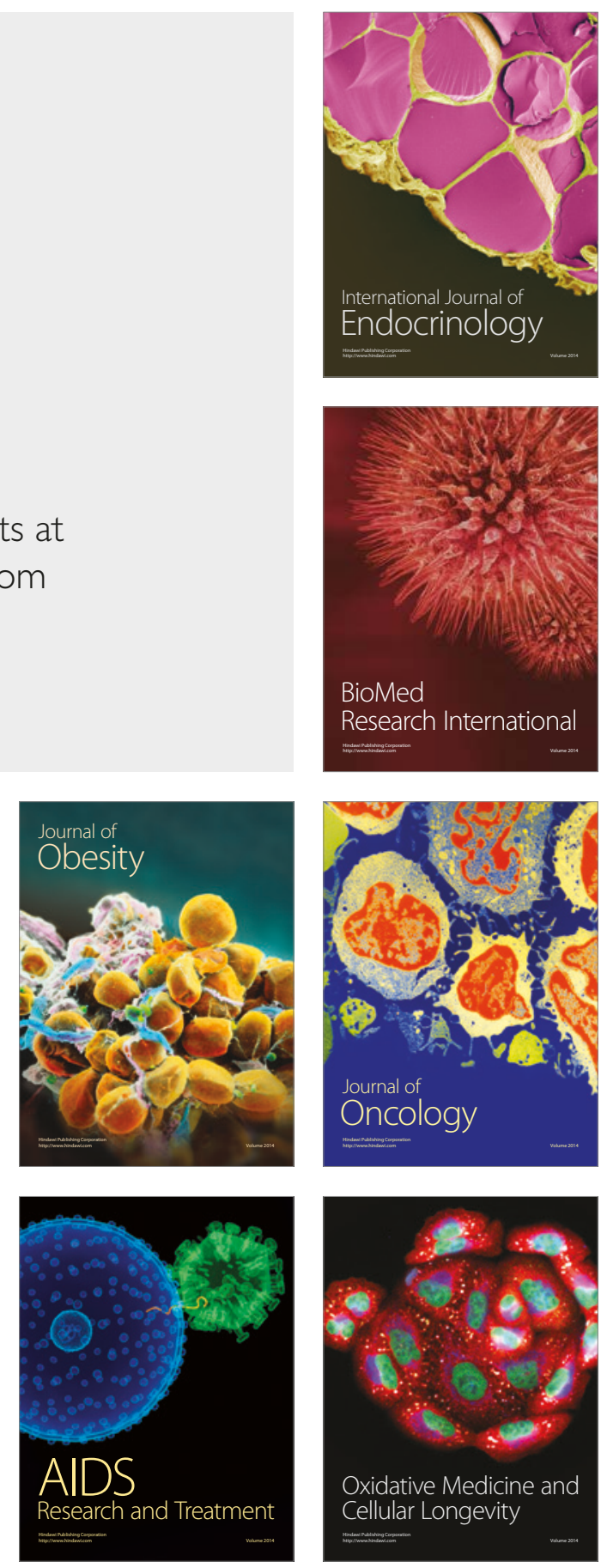